\title{
Management of the Maxillary Labial Frenum and Ankyloglossia Using Diode Laser at Single Visit: A Case Report
}

\author{
Lynn $\mathrm{J}^{1 *}$, Sana $\mathrm{F}^{2}$, Dimple Vaswani $\mathrm{A}^{3}$, Shanin $\mathrm{F}^{4}$, Vandita $\mathrm{A}^{5}$ and \\ Himanshu A $^{6}$ \\ ${ }^{1}$ Department of Periodontology and Oral Implantology, Maitri College of Dentistry and \\ Research Centre, India \\ ${ }^{2}$ Consulting Periodontist, Mumbai, India \\ ${ }^{3}$ Department of Oral Medicine and Radiology, Daswani Dental College, India
}

\section{Case Report}

Volume 2 Issue 3

Received Date: June 16, 2017

Published Date: July 28, 2017

DOI: $10.23880 /$ oajds- 16000138

${ }^{4}$ Department of Conservative Dentistry and Endodontics, Maitri College of Dentistry and Research Centre, India

${ }^{5}$ Consulting Periodontist, Mysore, India

${ }^{6}$ Consulting Periodontist, India

*Corresponding author: Lynn Johnson, Department of Periodontology and Oral Implantology, Maitri College of Dentistry and Research Centre, India, E-mail: lynnjohnson380@gmail.com

\begin{abstract}
The frenum is a mucous membrane fold that attaches the lip and the cheek to the alveolar mucosa, the gingiva, and the underlying periosteum. The frenum may jeopardize the gingival health when they are attached too closely to the gingival margin and may compromise the orthodontic result of the midline diastema cases, thus causing a recurrence after the treatment. Ankyloglossia or tongue-tie, refers to an abnormally short lingual frenum, causing problems with eating, speech and sometimes dyspnoea. Hence, it is necessary to perform a frenectomy in most cases. Various methods such as surgery, diathermy, and lasers have been used. In our study we have used Diode Laser for two frenectomies at the same visit, with number of advantages namely, no use of injectable anaesthesia or suture and no bleeding, pain, discomfort and swelling postoperatively with remarkable results at recalled visits for evaluation.
\end{abstract}

Keywords: Frenum; Ankyloglossia; Frenectomy; Diode Laser

\section{Introduction}

The word frenum is derived from the Latin word "fraenum" [1]. Oral frenum are band like formations of congenital origin located on the midline, which are composed of fibrous, muscular or fibro-muscular tissue, and are covered with a mucosal membrane [2]. Though Archer and Bisnoff stated that muscle fibers are found in the maxillary frenum, yet this has not been accompanied by histologic material. In contradiction, several articles and current texts state that no muscle is present. They are regarded as anatomical formations that, under normal conditions, do not have pathological consequences. However, in some cases they can present clinical problems, fundamentally of orthodontic, prosthetic, phonetic or periodontal nature [2]. The upper lip frenum is an oral mucosal membrane extending from the internal surface of the upper lip to its insertion on the midline of 


\section{Open Access Journal of Dental Sciences}

the attached interincisal gingival tissue of the upper maxilla $[1,2]$. In some cases, the frenum descends to the alveolar margin and inserts into the interdental papilla in the palatal vault [2]. When the insertion point of the frenum is at the gingival margin, papillary or papillary penetrating it may pose a problem. This kind of abnormal insertion of the frenum may cause marginal recession of the gingiva. Abnormal frenum insertion can distend and retract the marginal gingiva or papilla away from the tooth when the lip is stretched [1]. A frenum that encroaches on the margin of the gingiva may interfere with plaque removal, and tension on this frenum may tend to open the sulcus $[1,3]$.

To describe more accurately the location of the origin of the frenum, a morphologic functional classification of labial frenum attachments has been described as follows [4-6].

1. Mucosal attachment refers to an attachment of the frenum to the mucogingival junction.

2. Gingival attachment refers to an attachment of the frenum within the attached gingiva.

3. Papillary attachment refers to an attachment of the frenum within the papilla.
4. Papilla penetrating attachment refers to an attachment of the frenum passing through the papilla while inserting into attached gingiva (of the palate).

The tongue is attached to the floor of the mouth by fibrous band of tissues commonly referred to as the lingual frenum. The lingual frenum is described as the embryological remnant of tissue in the midline between the under surface of the tongue and the floor of the mouth that restricts normal tongue movement. Ankyloglossia is defined as a congenital abnormality of membrane attachment that fastens the tongue to the floor of the mouth thus interfering with its mobility resulting in speech and function impairment of the tongue [7]. It may also contribute to the development of anterior open bite due to the inability to raise the tongue to roof of mouth, which prevents the development of a normal swallowing pattern. It is also believed that ankyloglossia cases can be associated with upward and forward displacement of the epiglottis and larynx, resulting in various degrees of dyspnoea. It classified on the basis of "free tongue." Free tongue is defined as the length of tongue from the insertion of the lingual frenum into the base of the tongue to the tip of the tongue. Based on the length of free tongue, five categories can be distinguished (Table 1) [8].

\begin{tabular}{|c|c|}
\hline Type & Description \\
\hline Clinically acceptable & Normal, greater than $16 \mathrm{~mm}$ \\
\hline Class I & Mild ankyloglossia: 12 to $16 \mathrm{~mm}$ \\
\hline Class II & Moderate ankyloglossia: 8 to $11 \mathrm{~mm}$ \\
\hline Class III & Severe ankyloglossia: 3 to $7 \mathrm{~mm}$ \\
\hline Class IV & Complete ankyloglossia: less than $3 \mathrm{~mm}$ \\
\hline
\end{tabular}

Table 1: Classification of ankyloglossia.

To treat the abnormal frenum attachment either frenotomy or frenectomy can be done depending upon the attachment. Frenectomy is a complete removal of the frenum, including its attachment to the underlying bone, and may be required for correction of abnormal diastema between maxillary central incisors. Frenotomy is the incision and relocation of the frenal attachment. Frenectomy and frenotomy can be accomplished either by the routine scalpel technique, electrosurgery or by using lasers [1]. The use of lasers in soft tissue surgery has been explored in many previous studies. Different laser has been used for the same including Diode, Nd:YAG, Er:YAG, Er:Cr:YSGG, etc. We have used Diode Laser to treat our case. Diode is a solid active medium laser, manufactured from semiconductor crystals using some combination of aluminum or indium, gallium, and arsenic [9]. Since, the diode laser causes minimal damage to the periosteum and bone under the gingiva being treated as well as exhibits the unique property of being able to remove a thin layer of epithelium cleanly, it can be used for a variety of soft tissue procedures without impacting the neighbouring tissues [10].

\section{Case Report}

A 25 year old female patient referred from the Department of Orthodontics, came to the Department of Periodontology and Oral Implantology, Maitri College of Dentistry and Research Centre, Durg, Chhattisgarh with the chief complaint of forwardly placed upper and lower front teeth and difficulty in speech. Pull test revealed a papillary type of maxillary labial frenum attachment 
(Figure 1a). Moderate ankyloglossia was detected Kotlow's [7] classification (Figure 1b,c). As an adjunct to orthodontic treatment, a frenectomy procedure using Diode Laser $(810 \mathrm{~nm}$, Picasso; AMD) was planned immediately one after the other at the same visit for both the frena. The treatment procedure was explained to the patient and a written consent was signed. All the Laser safety precautions were taken into consideration. The setting used for the procedure is as follows:

For the maxillary labial frenum - 1W continuous contact mode

For lingual frenum: $0.8 \mathrm{~W}$ continuous contact mode using light-brush stroke motion

Resting interval was given during the procedure for thermal relaxation of the tissues. Both the frena were excised using the same technique. No injectable anaesthesia was required. The incision was carried out using the laser, the labial frenum along with connective tissue and fibrous attachments were removed (Figure 2d, e). The attachment of the frenum to the alveolar ridge was also excised to prevent any further tension on the gingiva. While performing the same procedure in the lingual frenum the tongue was held with a gauze piece by the assistant and frenum along with the connective tissue attachments was removed (Figure 2f) with laser settings as mentioned above (Figure $2 \mathrm{~g}$ ). High vacuum suction was used continuously to evacuate saliva and tissue plume. The fiber tip and the excision area were cleaned with a saline-damped gauze-piece frequently. The procedure was completed within 10 minutes and caused no discomfort to the patient. The surgical field was bloodless and there was no pain to the patient. No suturing was required. Postoperative instructions were given to the patient. The treated area was left to heal by secondary intention. Healing was uneventful and no scarring was seen even after 2 months (Figure 3-5). A one-day course of analgesic was given to the patient to be taken if needed.

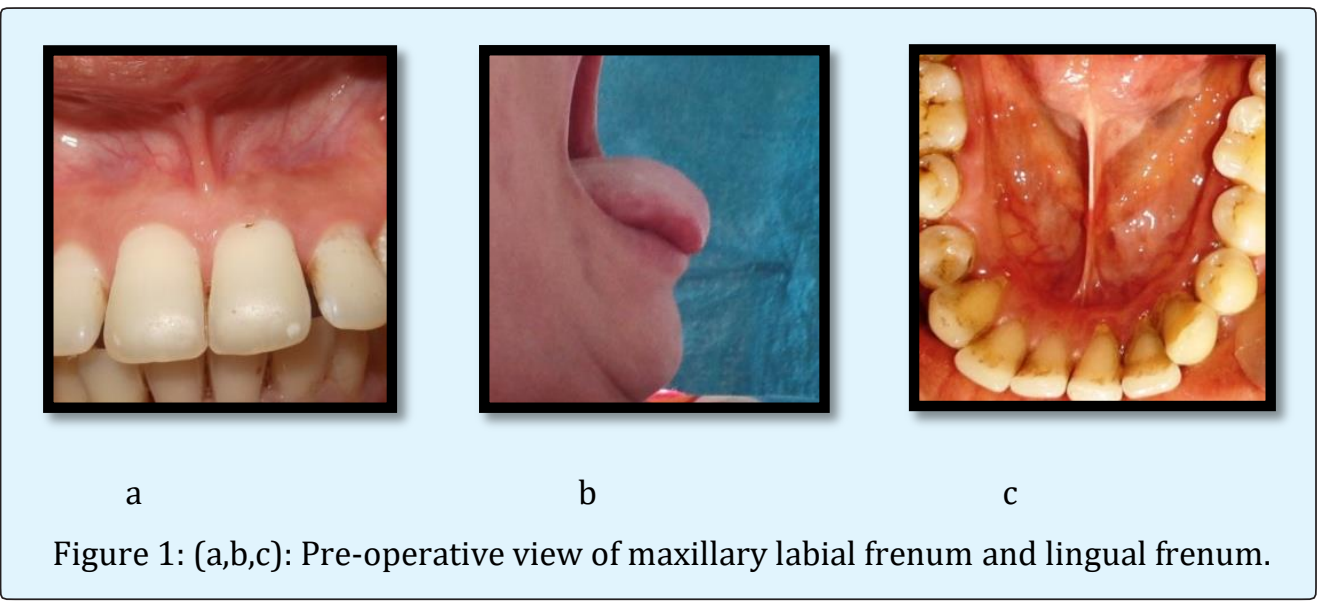

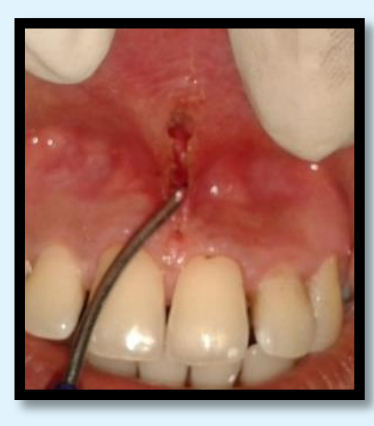

d

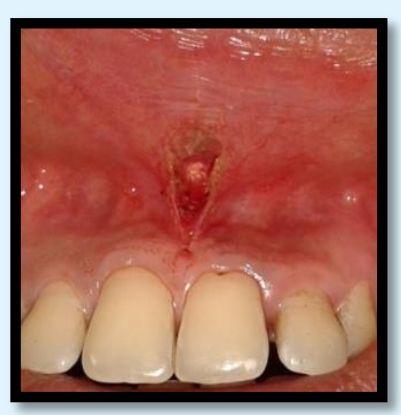

e

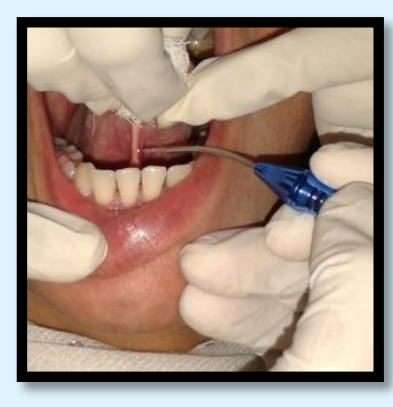

f

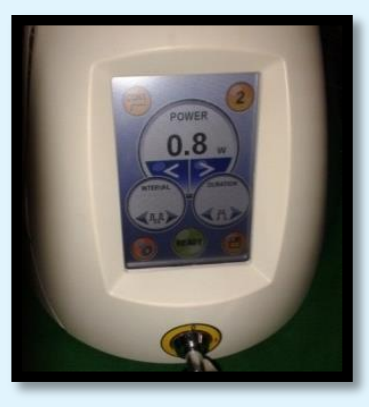

g

Figure 2 (d,e,f,g): Operative view of frenectomy being performed using the Diode Laser. 


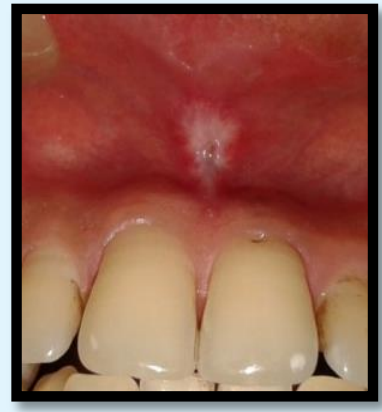

$\mathrm{h}$

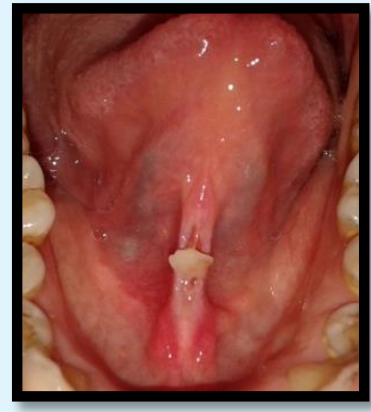

i

Figure 3 (h,i): Two-weeks post-operative view.

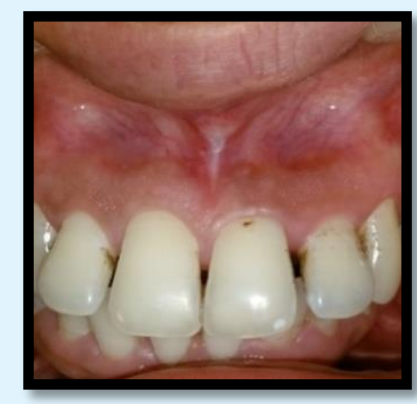

j

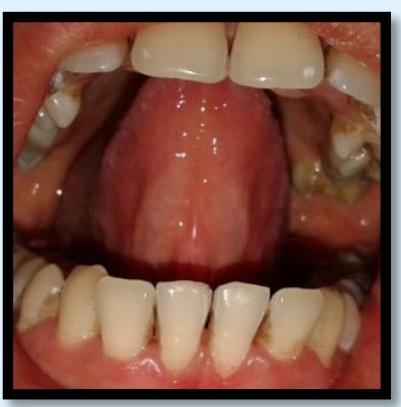

$\mathrm{k}$

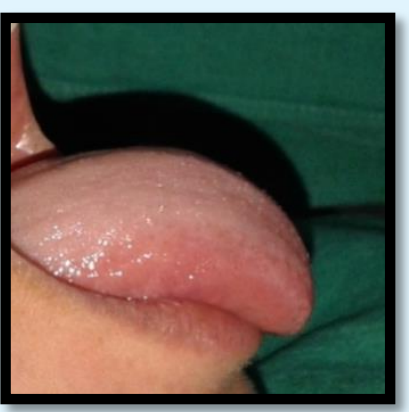

1

Figure $4(\mathrm{j}, \mathrm{k}, \mathrm{l})$ : Three-week post- operative view.

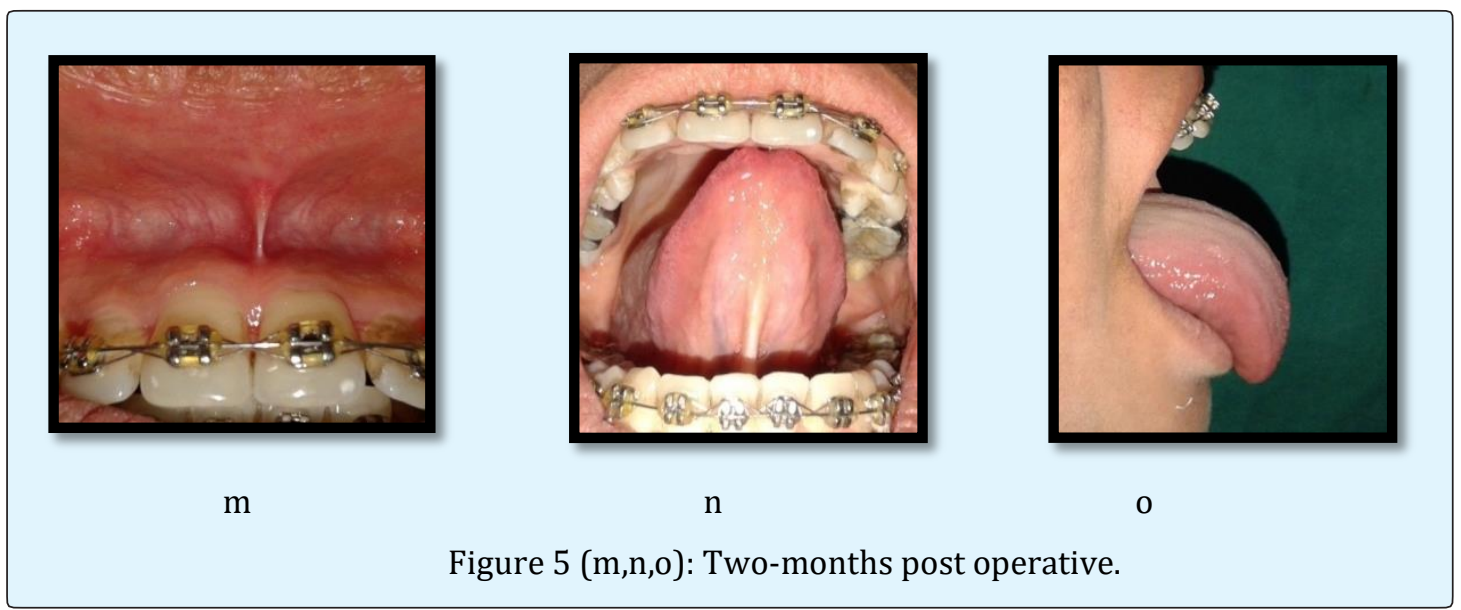




\section{Open Access Journal of Dental Sciences}

\section{Discussion}

The Diode Laser is now a viable alternative to the scalpel in soft tissue surgery. Because oral tissues are composed of $>90 \%$ water, and considering the affinity of the Diode Laser for wet tissue, it is readily applicable for most intraoral soft tissue surgery, including frenectomies [1]. Laser-assisted frenectomy is very easy to perform. The patient hardly experienced any discomfort and there was absolutely no bleeding. The excellent hemostasis and absence of postoperative swelling observed in our case can be attributed to a combination of sealing of small vessels through tissue protein denaturation and stimulation of factor VII production in clotting [4]. The heat buildup also allows for the sealing of small lymphatics and blood vessels. In addition, the laser's sterilization of the surgical wound reduces the need for postoperative care and antibiotics.8 Postoperative pain from oral and otolaryngeal surgical procedures has been claimed to be reduced in laser surgery. It is theorized that this may be due to the protein coagulum that is formed on the wound surface, thereby acting as a biologic dressing and sealing the ends of the sensory nerves [1]. Laser wavelength has affinity for melanin or dark pigments, and is strongly absorbed by the blood hemoglobin $[9,10]$, which contributes to their thermal effect. Therefore, laser works more efficiently when the energy is applied in the presence of pigments [11,12]. Thus, indicating reason behind the use of this range of wavelength for homeostasis [13] reported that the Diode Laser $(980 \mathrm{~nm})$ was beneficial in 22 patients when treating soft tissue tumors, gingival hyperplasia, frenectomy, removal of hemangioma, vestibuloplasty and peri-implant tissue surgery. The same authors concluded that the diode laser has postoperative advantages, i.e. lack of swelling, bleeding, pain, which is similar to our finding. Furthermore concluded that postoperative clinical findings were excellent due to the sufficient cutting abilities, good coagulation effect and extremely small zone of thermal necrosis to the nearby tissues using Diode Laser [14].

\section{Conclusion}

In conclusion, the use of laser is useful for a simple frenectomy due to their numerous advantages like no use of injectable anesthesia or suture and no bleeding even in critical areas like the lingual frenum which is prone to bleed due to its high vascularity. Patient was absolutely free of pain during and after the procedure, along with an absence of post-operative swelling. And most importantly two frenectomies were possible in a single sitting. Thus, practitioners should consider using diode laser in soft tissue surgical procedures for the benefit and comfort of the patient.

\section{References}

1. Kaur P, Dev YP, Kaushal S, Bhatia A, Vaid R, et al. (2014) Management of the upper labial frenum: a comparison of conventional surgical and lasers on the basis of visual analogue scale on patients perception. J Periodontal Med Clin Pract 1: 38-46.

2. Pie-Sanchez J, Espana-Tost AJ, Arnabat-Domínguez J, Gay-Escoda C (2012) Comparative study of upper lip frenectomy with the CO2 laser versus the Er, Cr: YSGG laser. Med Oral Patol Oral Cir Bucal 17(2): 228-232.

3. Haytac MC, Ozcelik O (2006) Evaluation of Patient Perceptions after Frenectomy Operations: A Comparison of Carbon Dioxide Laser and Scalpel Techniques. J Periodontol 77(11): 1815-1819.

4. Mirko P, Miroslav S, Lubor M (1974) Significance of the Labial Frenum Attachment in Periodontal Disease in Man. Part 1. Classification and Epidemiology of the Labial Frenum Attachment. J Periodontol 45(12): 891-894.

5. Christabel SL, Deepa G (2015) Prevalence of type of frenal attachment and morphology of frenum in children, Chennai, Tamil Nadu. World J Dent 6(4): 203-207.

6. Priyanka M, Sruthi R, Ramakrishnan T, Emmadi P, Ambalavanan $N$ (2013) An overview of frenal attachments. J Indian Soc Periodontol 17(1): 12-15.

7. Kotlow L (2011) Diagnosis and treatment of ankyloglossia and tied maxillary frenum in infants using Er:YAG and 1064 diode lasers. Eur Arch Paediatr Dent 12(2): 106-112.

8. Yogesh D, Mona S, Nikhil K, Ankit S (2010) Advantages of Diode Laser ( $940 \mathrm{~nm})$ over Surgical Blade in Management of Ankyloglossia: A Case Report. J Oral Laser Applications 10(4): 165-169.

9. Coluzzi DJ (2004) Fundamentals of dental lasers: science and instruments. Dent Clin N Am 48(4): 751770 . 


\section{Open Access Journal of Dental Sciences}

10. Vivek G, Minkle G, Smita G (2011) Diode laser applications in periodontics. Indian Journal of Dental Sciences 3(5): 64-67.

11. Butchibabu K, Koppolu P, Mishra A, Pandey R, Swapna LA, et al. (2014) Evaluation of patient perceptions after labial frenectomy procedure: A comparison of diode laser and scalpel techniques. Eur J Gen Dent 3(2): 129-133.

12. Singh P, Gulati RK, Agarwal RR, Khan F (2016) Laser assisted frenectomy-a case report. Annals of Dental Specialty 4(1): 18-19.
13. Aldelaimi TN, Mahmood AS (2014) Laser-assisted frenectomy using $980 \mathrm{~nm}$ diode laser. J Dent Oral Disord Ther 2(4): 1-6.

14. Gabric Panduric D, Ivona Bago, Filipovic Zore I, Susic M, Katanec D, et al. (2013) Application of Diode Laser in Oral and Maxillofacial Surgery. A Textbook of Advanced Oral and Maxillofacial Surgery 13: 341-382. 